\title{
A Myasthenia Gravis Case Diagnosed Simultaneously with Diabetic Ketoacidosis
}

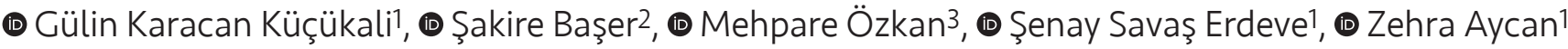

'Ankara Dr. Sami Ulus Obstetrics and Gynecology Children's Health and Disease Training and Research Hospital, Clinic of Pediatric Endocrinology, Ankara, Turkey

${ }^{2}$ Ankara Dr. Sami Ulus Obstetrics and Gynecology Children's Health and Disease Training and Research Hospital, Clinic of Pediatrics, Ankara, Turkey ${ }^{3}$ Ankara Dr. Sami Ulus Obstetrics and Gynecology Children's Health and Disease Training and Research Hospital, Clinic of Pediatric Neurology, Ankara, Turkey

\begin{abstract}
Juvenile myasthenia gravis (JMG) is an autoimmune disease caused by antibodies affecting the postsynaptic membrane at the neuromuscular junction. The association of JMG with Type I diabetes mellitus (DM), another autoimmune disease, is very rare and the pathogenesis has not been fully explained. Our case is the youngest patient where this association has been reported in the literature and presented at the age of 4 years when diabetic ketoacidosis developed together with the emergence of ocular myasthenia findings. She is the only case diagnosed with IMG among the 510 Type I DM patients followed-up at our clinic. Although an autoimmune process may have triggered both autoimmune diseases at the same time in this case, we believe the diabetic ketoacidosis was a triggering factor for the JMG and discuss this association.
\end{abstract}

Keywords: Type I diabetes mellitus, diabetic ketoacidosis, juvenile myasthenia gravis

\section{Introduction}

Type I diabetes is an organ-specific autoimmune disease which is characterized by the selective destruction of pancreatic beta cells. Genetic predisposition, autoimmunity and viral infections are the main etiopathological factors in the pathogenesis. Although, other autoimmune diseases such as autoimmune thyroid disorders, adrenal disorders, celiac disease and connective tissue disorders may be associated with Type I diabetes mellitus (DM), the association of myasthenia gravis and Type I diabetes is very rare $(1,2)$.

Juvenile myasthenia gravis (JMG) is an autoimmune disease in which antibodies are directed against the postsynaptic membrane of the neuromuscular junction, resulting in muscle weakness and fatigability. The incidence of JMG is between 1.0 and 5.0 per 1.000 .000 per year (3). In many patients, the autoimmune response is regulated with antibodies developing against acetylcholine receptors (AChR). Antibodies to muscle-specific kinase (MuSK) and to Leucine rich protein 4 have been reported in some seronegative patients $(4,5)$. The diagnosis of JMG requires a detailed history, repeated physical examinations, neurophysiological investigations, and antibody evaluations $(4,6)$.

JMG association was reported only in $1(0.38 \%)$ of 260 children with Type I diabetes during 14 years of follow-up in a series (7). The coexistence of JMG, primary adrenal deficiency and Type I DM has previously been reported

Address for Correspondence

Gülin Karacan Küçükali MD, Ankara Dr. Sami Ulus Obstetrics and Gynecology Children's Health and Disease Training and Research Hospital, Clinic of Pediatric Endocrinology, Ankara, Turkey

Phone: +90 5337648426 E-mail: gulinkucukali@gmail.com ORCID ID: orcid.org/0000-0001-7506-1711

Received: 29.01.2018 Accepted: 30.04.2018

${ }^{(\odot)}$ Copyright 2019 by Ege University Faculty of Medicine, Department of Pediatrics and Ege Children's Foundation

The Journal of Pediatric Research, published by Galenos Publishing House. 
in a 12-year-old child (8). Our case has been reported as the coexistence of ocular myasthenia gravis and diabetic ketoacidosis at the age of 4 years with the aim of discussing the Type I DM and JMG association.

\section{Case Report}

A 4-year-old female patient presented to the emergency service due to rapid breathing and sleepiness for 2 days. We found no unusual feature about her personal and the family history. It was reported that patient had drank a lot of water and experienced increased urination for the last month resulting with weight loss that had become more evident in the prior week. Her physical examination revealed moderate general condition; body temperature: $36.7{ }^{\circ} \mathrm{C}$, respiratory rate: 40/min, pulse rate: 120/min, oxygen saturation: $95 \%$, and arterial blood pressure: 90/60 mm/Hg. Moreover, the patient had dry mouth, sunken eyeballs, acidotic breathing and she was weak. The laboratory test results of the patient showed that, hemoglobin: $13.2 \mathrm{~g} / \mathrm{dL}$, white blood cells: $9.810 / \mathrm{mm}^{3}$, platelets: $229.000 \mathrm{~mm}^{3}$, blood glucose: $697 \mathrm{mg} / \mathrm{dL}$, sodium ( $\mathrm{Na}$ ): $128 \mathrm{meq} / \mathrm{L}$, corrected $\mathrm{Na}: 137.5 \mathrm{meq} / \mathrm{L}$, potassium: $3.6 \mathrm{meq} / \mathrm{L}$, chlor: $104 \mathrm{mEq} / \mathrm{L}$, calcium: $8.4 \mathrm{mg} / \mathrm{dL}$, phosphate: $2.7 \mathrm{mg} / \mathrm{dL}$, blood urea nitrogen: $7 \mathrm{mg} / \mathrm{dL}$, creatinine: $0.58 \mathrm{mg} / \mathrm{dL}$, uric acid: $4 \mathrm{mg} / \mathrm{dL}$, SGOT: $15 \mathrm{U} / \mathrm{L}$, SGPT: $16 \mathrm{U} / \mathrm{L}$, total bilirubin: $0.3 \mathrm{mg} / \mathrm{dL}$, total protein: $6.8 \mathrm{~g} / \mathrm{dL}$, albumin: $4.2 \mathrm{~g} / \mathrm{dL}$, hemoglobin A1c: $14.8 \%$ (4.6-6.2), c peptide: $0.12 \mathrm{ng} / \mathrm{mL}$ (0.9-4), blood gas $\mathrm{pH}: 7.11, \mathrm{pCO}_{2}: 15.6 \mathrm{mmHg}, \mathrm{HCO}_{3}: 8.7$ $\mathrm{mmol} / \mathrm{L}$, base deficit: -22.4 , and positive blood and urine ketones. On the basis of these findings, the patient was diagnosed as diabetic ketoacidosis. Moreover, with the evaluation of her dehydration; we decided that she had $2^{\text {nd }}$ degree dehydration. Accordingly, we applied $0.9 \%$ sodium chloride which was loaded for 1 hour at $20 \mathrm{~mL} / \mathrm{kg}$. Then, she was admitted to the intensive care unit where we started infusion of intravenous fluids and insulin. The ketosis and acidosis improved at the $21^{\text {st }}$ hour and then it was possible to feed her orally. Then, enteral nutrition and subcutaneous insulin were started. The bilateral ptosis that was found at presentation continued after the diabetic ketoacidosis had improved and became more evident at follow-up. Her history revealed that the ptosis had first started mildly 2 days before presentation and had increased in a short time. Also, her symptom became more severe after physical activity and it had minimal diurnal variation. We observed that the ptosis became worse in the evening and it improved after resting. We found no signs of weakness of the facial, neck, bulbar, limb and respiratory muscles. The ptosis was not present in pictures of the patient that were taken 1 month before the diabetic ketoacidosis developed, indicating that it had emerged during the diabetic ketoacidosis development period (Figures 1, 2). The fatigue test was performed with a preliminary diagnosis of ocular $\mathrm{MC}$. The test revealed that the ptosis increased after prolonged upgaze and improved after the ice test which supported the preliminary diagnosis (Figure 3). Repetitive nerve stimulation of the median and ulnar nerves showed no significant amplitude decrements. We did not perform IV or IM edrophonium tests on our patient due to the possible side effects and lack of edrophonium in our country. We started oral pyridostigmine $0.5 \mathrm{mg} / \mathrm{kg} /$ day every 6 hours and gradually increased the dose to $1 \mathrm{mg} / \mathrm{kg} /$ day every 6 hours over several days. The third dose of pyridostigmine improved the bilateral ptosis. Serum AChR antibodies and muscle-specific tyrosine kinase antibodies were both negative. The diagnosis

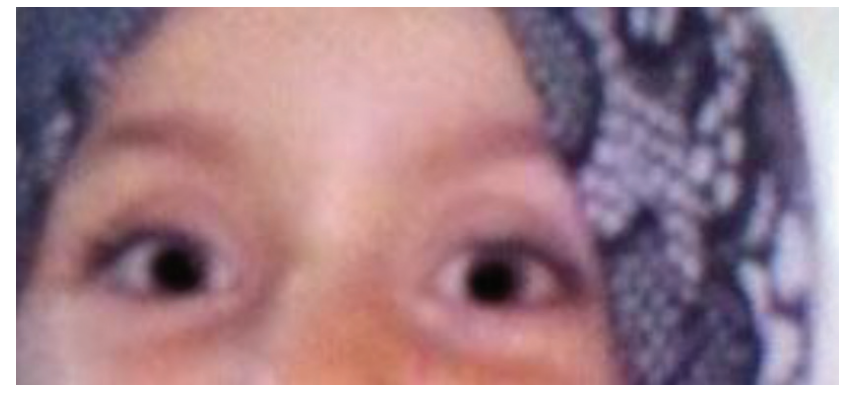

Figure 1. The patient before ptosis development

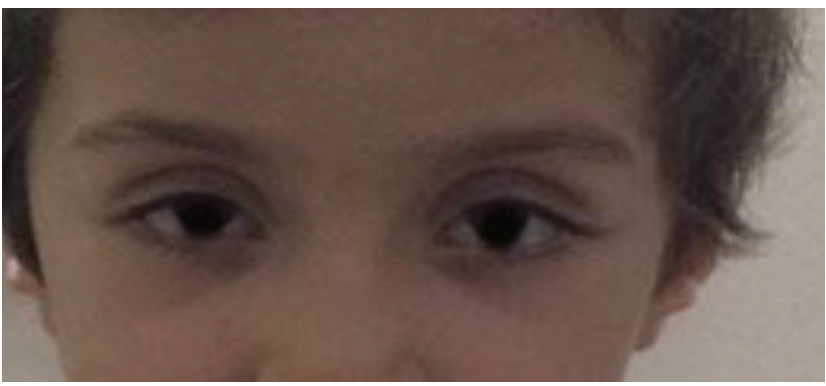

Figure 2. The ptosis that developed in the diabetic ketoacidosis period

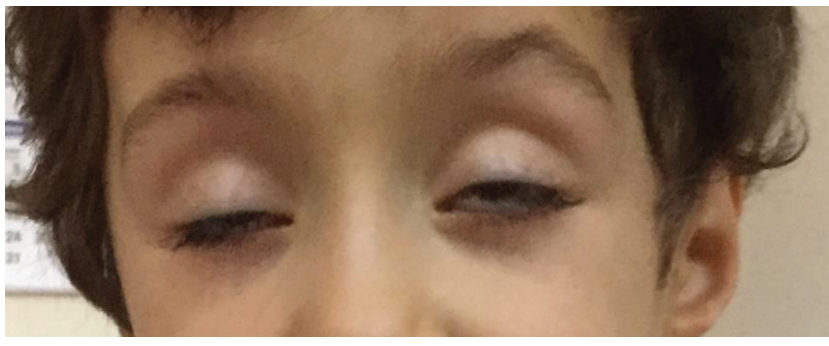

Figure 3. The fatigue test performed with diagnosis of ocular myasthenia gravis revealed that the ptosis increased after prolonged upgaze 
was double-seronegative ocular myasthenia gravis. Magnetic resonance imaging of the brain revealed no abnormalities. Chest X-ray obtained focusing on thymoma was normal. Evaluation regarding possible concurrent autoimmune disease revealed the following: islet cell antibody: negative, anti-insulin antibody: 2.71\% (0-7), anti-GAD: $37.06 \mathrm{U} / \mathrm{mL}(0-1), \mathrm{TSH}: 1.93 \mu \mathrm{IU} /$ $\mathrm{mL}(0.6-6.3)$, sT4: $1.18 \mathrm{ng} / \mathrm{dL}(0.9-2.1), \mathrm{sT3}: 2.71 \mathrm{pg} / \mathrm{mL}$ (2-6.5), anti TPO: $41.3 \mathrm{lU} / \mathrm{mL}$ (0-60), anti-thyroglobulin: 17.1 (0-60), tissue transglutaminase immunoglobulin $A$ $(\lg \mathrm{A})$ : positive, tissue transglutaminase $\lg \mathrm{G}$ : negative, anti-endomysium IgA: positive, anti-gliadin IgA: positive, anti-gliadin IgG: negative, cortisol: $18.11 \mu \mathrm{g} / \mathrm{dL}$ (5-22), and adrenocorticotropic hormone: $14.9 \mathrm{pg} / \mathrm{mL}$ (0-46).

The patient's blood glucose was regulated with intensive insulin treatment, the ptosis improved with pyridostigmine and diabetes education was completed. She was discharged to follow-up with a diagnosis of seronegative ocular MG. Informed consent from patient's family was received.

\section{Discussion}

Type I DM can be accompanied by other autoimmune diseases such as thyroid diseases, adrenal diseases, and celiac disease (1). JMG patients are also under increased risk of comorbid autoimmune disease such as thyroid disease, systemic lupus erythematosus and rheumatoid arthritis. The mechanism regarding the development of multiple autoimmune disorders is unclear. The human leukocyte antigen locus is still the risk factor showing the strongest association with autoimmune disorders including JMG (9).

The Type I DM and JMG association is very rare and only 2 cases have been reported so far $(7,8)$. The Type I DM and JMG association was only found in 1 patient in a study where 260 Type I DM patients were monitored. This male case, whose age was not reported, presented with an acute myasthenia gravis attack and was treated with intravenous immunoglobulin and plasmapheresis (7). Primary adrenal deficiency and Type I DM association with JMG was reported in another 12-year-old patient (8). Our case is different from existing studies since our case is probably the youngest patient to be diagnosed and the symptoms appeared during the clinical diabetic ketoacidosis development period. Moreover, she is the only patient diagnosed with JMG among the 510 Type I DM patients followed-up at our clinic, resulting in an $0.19 \%$ rate for JMG among our Type I DM patients.

JMG is rare in Europe and makes up 10-15\% of all myasthenia gravis cases in Caucasians (6). Peri- or postpubertal children presenting with JMG share more similarities with adult-onset MG and also show increased association with other autoimmune disorders (4). The coexistence of these two autoimmune disorders during the prepubertal period is interesting in our patient. The diagnosis in younger children constitutes a particular challenge as non-specific symptoms may be present or the antibodies are only minimally elevated or even normal. While anti-AChR and anti-MUSK were negative in our case; the JMG diagnosis was made with the presence of ocular symptoms that started during diabetic ketoacidosis development. Besides, the positive fatigue test and the improvement of ocular symptoms with pyridostigmine supported our diagnosis in the previously healthy patient. Some young children, as in our patient, who are negative for AChR antibodies will have "low affinity" antibodies to AChR that are not detectable using standard assays (10). Ocular symptoms only are seen in $15 \%$ of the patients with myasthenia gravis and this group makes up the pure ocular form. Patients who present with an ocular form are recommended to be followed-up for a minimum of 2 years before being classified as the pure ocular form (6). Presentation with ocular symptoms is more common in patients with prepubertal JMG, as in our patient. We will be following-up our patient in terms of generalized $\mathrm{MG}$ development.

It is interesting that the ocular MG symptoms of our previously healthy patient emerged with the diabetic ketoacidosis clinical picture. However, both autoimmune disorders can be seen together and the autoimmune process could have triggered both autoimmune disorders at the same time. Hence, it is possible that diabetic ketoacidosis may also be a triggering factor.

In conclusion, the Type I DM and JMG combination in the prepubertal period has not been reported until now as far as we know and it is important for clinicians to be aware of this combination and the possibility of an association between various autoimmune disorders in order to improve disease outcomes.

\section{Ethics}

Informed Consent: Informed consent from patient's family was received.

Peer-review: Externally peer-reviewed.

\section{Authorship Contributions}

Surgical and Medical Practices: M.Ö., Ş.S.E., Concept: M.Ö., Z.A., Design: Z.A., Ş.S.E., Data Collection or Processing: G.K.K., Ş.B., Ş.S.E., Analysis or Interpretation: M.Ö., Ş.S.E., Literature Search: G.K.K., Ş.B., Ş.S.E., Writing: G.K.K., Ş.B., S.S.E. 
Conflict of Interest: No conflict of interest was declared by the authors.

Financial Disclosure: There are no financial conflicts of interest to disclose.

\section{References}

1. Redondo M), Eisenbarth GS. Genetic control of autoimmunity in Type 1 diabetes and associated disorders. Diabetologia 2002;45:605-22.

2. Kawasaki E. Type 1 Diabetes and Autoimmunity. Clin Pediatr Endocrinol 2014;23:99-105.

3. McGrogan A, Sneddon S, deVries CS. The incidence of myasthenia gravis: a systematic literature review. Neuroepidemiology 2010;34:171-83

4. Marina AD, Trippe $H$, Lutz $S$, Schora V. Juvenile myasthenia gravis: recommendations for diagnostic approaches and treatment. Neuropediatrics 2014;45:75-83.
5. Pevzner A, Schoser B, Peters K, et al. Anti-LRP4 autoantibodies in AChR- and MuSK-antibody-negative myasthenia gravis. I Neurol 2012;259:427-35.

6. Berrih-Aknin S, Frenkian-Cuvelier M, Eymard B. Diagnostic and clinical classification of autoimmune myasthenia gravis. I Autoimmun 2014;48-49:143-8.

7. Kota SK, Meher LK, Jammula S, Kota SK, Modi KD. Clinical profile of coexisting conditions in Type I diabetes mellitus patients. Diabetes Metab Syndr 2012;6:70-6.

8. AndlerW. Myasthenia gravis, primer adrenocortical insufficiency, and juvenile diabetes mellitus in a twelve-year-old boy. Klin Padiatr 1983;195:133-4.

9. Gilhus NE, Nacu A, Andersen JB, Owe JF. Myasthenia Gravis and risks for comorbidity. Eur I Neurol 2015;22:17-23.

10. Leite MI, Jacob S, Viegas S, Cossins I, Clover L, Morgan BP, Beeson D, Willcox N, Vincent A. IgG1 antibodies to acetylcholine receptors in 'seronegative' myasthenia gravis. Brain 2008;131:1940-52. 